\title{
Comments on "Thermoelectric properties of rare earth containing type-I clathrate compound, $\mathrm{Dy}_{8} \mathrm{Al}_{16} \mathrm{Si}_{30}$ "
}

\author{
T. Himmelbauer ${ }^{1} \cdot$ A. Prokofiev $^{1}$ (D)
}

Received: 1 August 2016/Accepted: 29 August 2016/Published online: 3 September 2016

(c) The Author(s) 2016. This article is published with open access at Springerlink.com

\begin{abstract}
In the paper by K. Rajput and S. Vitta published in the present journal the synthesis and the thermoelectric properties of the dysprosium containing clathrate $\mathrm{Dy}_{8} \mathrm{Al}_{16} \mathrm{Si}_{30}$ were reported. We prepared two samples following exactly to the technique described in the paper. Our XRD and SEM/EDX investigations do not confirm the presence of any amount of a Dy-containing clathrate phase in the sample.
\end{abstract}

In the recent paper by K. Rajput and S. Vitta [1] the synthesis and the thermoelectric properties of the dysprosium containing clathrate $\mathrm{Dy}_{8} \mathrm{Al}_{16} \mathrm{Si}_{30}$ were reported. The authors obtained by melting the elementary metals a polyphase material containing, as claimed by the authors, the clathrate phase. This conclusion was made on the basis of X-ray powder diffraction (XRD) of the polyphase sample. However, in our opinion, the diffraction pattern and the Rietveld analysis given in the paper do not provide strong evidence of the presence of the clathrate phase. The authors investigated the sample also using the scanning electron microscopy (SEM) with energy dispersive X-ray spectral analysis (SEM/EDX). However, only the total composition of the sample and not that of the individual phases was reported.

A. Prokofiev

andrey.prokofiev@ifp.tuwien.ac.at

1 Institute of Solid State Physics, Vienna University of Technology, Wiedner Hauptstr. 8-10, 1040 Vienna, Austria
We prepared a sample following exactly to the technique described in the paper (Tetra-Arc Techno Search) with annealing of a part of the sample at $780 \mathrm{~K}$ for 7 days. The as-cast and the annealed samples were characterized by XRD (PANalytical XPert Pro MPD, X-ray Center TUWien) and SEM/EDX (Philips XL30 ESEM, EDAX New XL-30 135-10 UTW). The powder diffraction patterns obtained by us were very similar to the reported in Ref. [1]. The Rietveld refinement of the samples $\left(\mathrm{R}_{\mathrm{wpr}}=2.8 \%\right)$ yields the following phases (mass. \%): ascast sample-Si 45, $\mathrm{DySi}_{2} 22, \mathrm{DyAl}_{2} \mathrm{Si}_{2}$ 17, Al 16; annealed sample-Si 59, DyAl ${ }_{2} \mathrm{Si}_{2} 28, \mathrm{DySi}_{1.78} 4$; Al 7, $\mathrm{Dy}_{2} \mathrm{Al}_{3} \mathrm{Si}_{2} 2$ (Fig. 1).

No clathrate phase was detected in both our samples. Although the diffraction pattern of the Dy-clathrate is not available, it can be simulated based on the existing $\mathrm{Ba}-$ and Sr-containing analogues. Substitution of $\mathrm{Ba}$ with its ionic radius $\left(r_{i o n}\right)$ of $1.47 \AA$ by $\mathrm{Sr}$ with $r_{i o n}=1.31 \AA$ results in a contraction of the unit cell from $a=10.632$ to $10.465 \AA$ $[2,3]$. Linear extrapolation to the ionic radius of $\mathrm{Dy}^{3+}$ $r_{i o n}=1.083 \AA$ leads to a value of $a=10.23 \AA$ for the lattice constant of the Dy-clathrate. Using this value and replacing the scattering factor of $\mathrm{Ba}$ by that of $\mathrm{Dy}$ we obtained the diffraction pattern of a hypothetical Dyclathrate which is shown in Fig. 1 as a line diagram.

The polished surfaces of the samples were analyzed by SEM with EDX measurements of the compositions of all individual constituting phases (Fig. 2). The analysis confirms the presence of phases found by the powder diffraction.

No phase with the generic composition $\mathrm{A}_{8} \mathrm{~B}_{46}$ characteristic of a type-I clathrate was found.

Thus both XRD and SEM/EDX do not confirm the presence of any amount of a Dy-containing clathrate phase in the sample prepared according to [1]. 

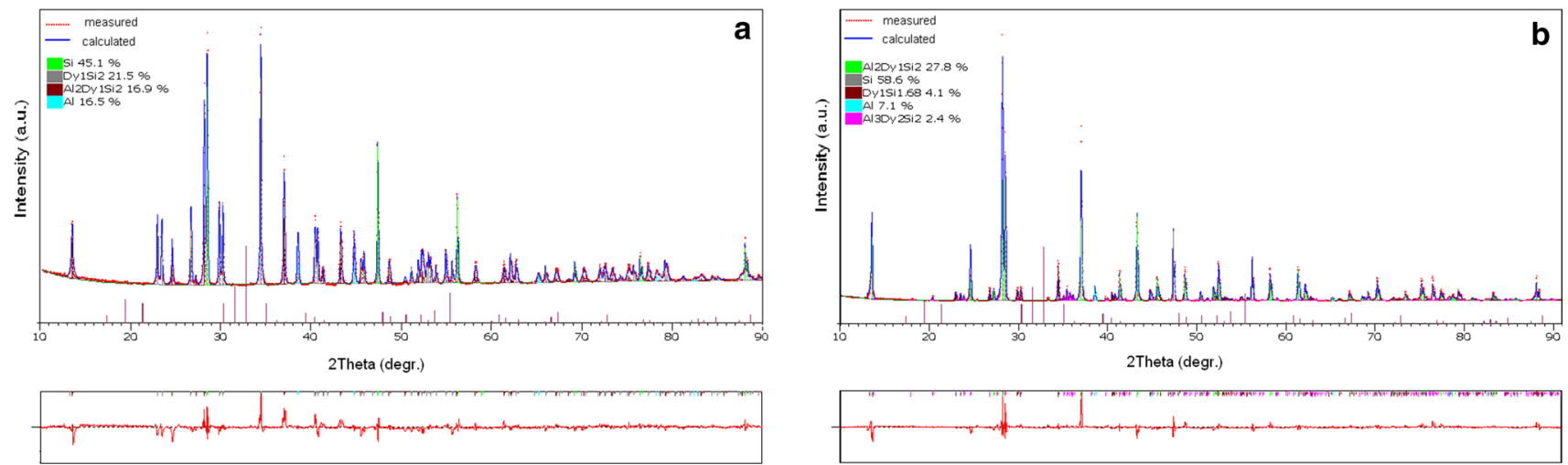

Fig. 1 X-ray diffraction patterns of the as-cast (a) and the annealed (b) samples with their Rietveld refinement profiles. The phase compositions are shown in mass. \%. The lines show the positions and the relative intensities of the peaks of the hypothetical $\mathrm{Dy}_{8} \mathrm{Al}_{16} \mathrm{Si}_{30}$ clathrate phase
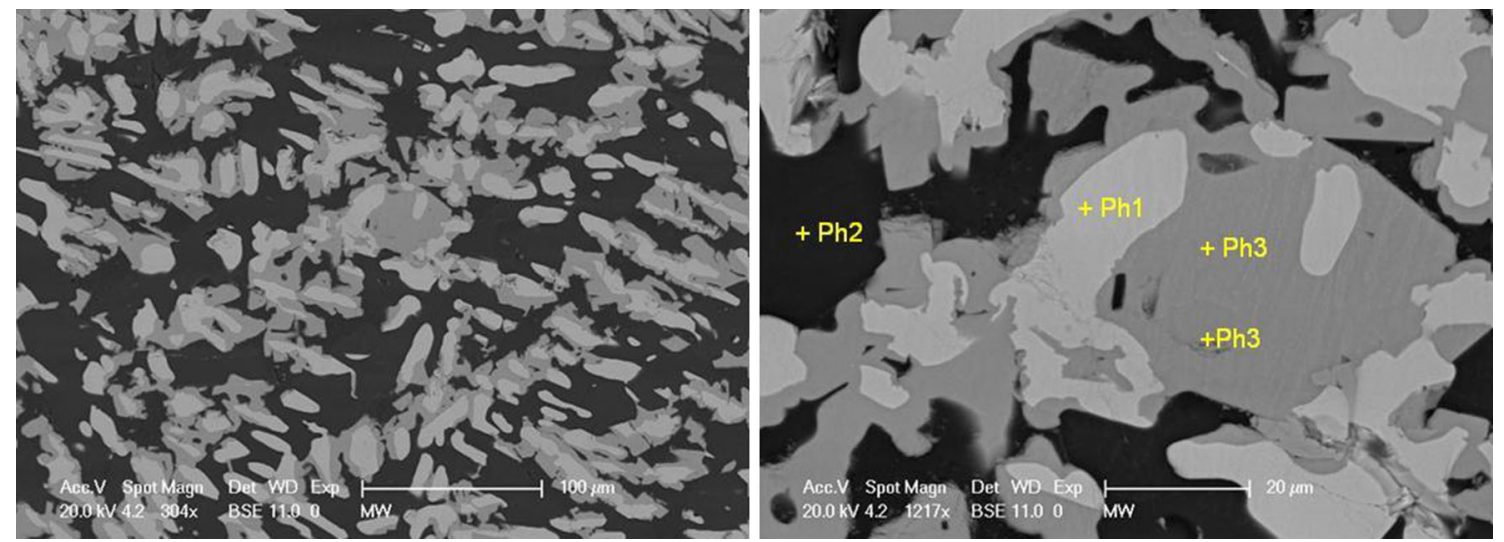

Fig. 2 SEM image of the polished surface of the as-cast sample at two different magnifications. The composition of the main phases: Ph1$\operatorname{Dy}\left(\mathrm{Si}_{1-\mathrm{x}} \mathrm{Al}_{\mathrm{x}}\right)_{1.75}(\mathrm{x} \approx 0.1), \mathrm{Ph} 2-\mathrm{Si}, \mathrm{Ph} 3-\mathrm{DySi}_{2-\mathrm{y}} \mathrm{Al}_{2+\mathrm{y}}(\mathrm{y} \approx 0.1)$

Acknowledgements Open access funding provided by TU Wien (TUW).

Open Access This article is distributed under the terms of the Creative Commons Attribution 4.0 International License (http://crea tivecommons.org/licenses/by/4.0/), which permits unrestricted use, distribution, and reproduction in any medium, provided you give appropriate credit to the original author(s) and the source, provide a link to the Creative Commons license, and indicate if changes were made.

\section{References}

1. K. Rajput, S. Vitta, J. Mater. Sci. Mater. Electron. (2016). doi:10. 1007/s10854-016-5113-1

2. N. Tsujii, J.H. Roudebush, A. Zevalkink, C.A. Cox-Uvarov, G.J. Snyder, S.M. Kauzlarich, J. Solid State Chem. 184, 1293 (2011)

3. J.H. Roudebush, N. Tsujii, A. Hurtando, H. Hope, Y. Grin, S.M. Kauzlarich, Inorg. Chem. 51, 4161 (2012) 